\title{
Radiological Clinical Case of Klippel-Feil Syndrome
}

\author{
V. A. Sorokovikov, PhD, ScD; P. V. Seliverstov, PhD, ScD*; \\ N. A. Pozdeeva, PhD; U. V. Pichugina, PhD; V. A. Safonov \\ Irkutsk Scientific Center of Surgery and Traumatology \\ Irkutsk, Russia
}

\begin{abstract}
Klippel-Feil syndrome (KFS) is a genetically determined anomaly of the cervical spine characterized by the abnormal fusion of vertebrae. The clinical signs are a shortness and a restricted mobility of the neck and a low hairline at the back of the head. KFS is typically associated with many other abnormalities of the skeleton and other systems. The clinical case of KFS first diagnosed in an adult is demonstrated in this review.(International Journal of Biomedicine. 2021;11(2):181-183.)
\end{abstract}

Key Words: Klippel-Feil syndrome $\bullet$ vertebrae $\bullet$ cervical spine $\bullet$ spina bifida

For citation: Sorokovikov VA, Seliverstov PV, Pozdeeva NA, Pichugina UV, Safonov VA. Radiological Clinical Case of KlippelFeil Syndrome. International Journal of Biomedicine. 2021;11(2):181-183. doi:10.21103/Article11(2)_CR2

\section{Introduction}

Klippel-Feil syndrome (KFS) is a rare condition: The prevalence is about 1 in 120,000 newborns but there are no precise data due to lack of population studies. KFS was first described in 1912 in France by neurologist Maurice Klippel and radiologist Andre Feil. This pathology is related to hypoplasia or aplasia of vertebrae, disturbance of cervical segmentation, and retarding of their fusion in the first weeks of gestation. ${ }^{(1,2)}$ There are many hypotheses of KFS development: a vascular disorder, an anomaly of the neural tube, a genetic predisposition, and an insufficiency of facet joint segmentation. It is also thought that it could be the result of mother's alcohol abuse or fetal alcohol syndrome, though the precise cause of the pathology is unknown. ${ }^{(2-4)}$

A. Feil has classified this syndrome into 3 types. Type I (KFS1) presents a reduced number of cervical vertebrae, usually 4-5. Type II (KFS2) is a synostosis of cervical spinal bodies, the fusion of occipital bone and upper thoracic spine. Type III demonstrates a combination of Type I and Type II

*Corresponding author: Pavel V. Seliverstov, MD, PhD, ScD. Department of Radiology and Minimally Invasive Surgery, Irkutsk Scientific Center of Surgery and Traumatology. Irkutsk, Russia. E-mail:pavv2001@gmail.com with the fusion in the lower thoracic and lumbar spine. The accessory ribs and the spina bifida (incomplete closing of the spinal arcus) are often seen in the cervical spine.

The main clinical triad of findings, typical for KFS, are a short neck, a low posterior hairline, and a limited cervical range of motion. The stage of the shortness of neck varies: In the most severe variant the ear lobes could reach the shoulders, the chin could touch the sternum, and swallowing and breathing are difficult. A wide spreading and a shortening of scapulas are characteristic, an elevation of scapula so typical for Sprengel disease could be seen. In some cases, there are the abnormalities of shoulder muscles and wrinkles on the neck, only rarely a radiculopathy arises, caused by compression of the cervical nerve roots. This syndrome has a negative impact on the internal systems, can provoke a development of severe complications and requires a long-term treatment. A conservative therapy for children with KFS includes massage, medical gymnastics, and physiotherapy. Surgery, such as cervicalisation, is also possible. The prognosis is good for individuals without somatic malformations, but these patients have some serious aesthetic and functional problems.

Verification of diagnosis is based on the typical triad of signs after birth, examination findings, family anamnesis, diagnostic imaging, and genetic analyses. It is possible to diagnose KFS with a detailed description of concomitant 
anomalies only as a result of the collaboration of different specialists: neurologist, orthopedist, geneticist, cardiologist, nephrologist, pulmonologist, ophthalmologist. ${ }^{(5-12)}$

\section{Case Presentation}

A 33-year-old white man presented to the radiological department of Irkutsk Scientific Center of Surgery and Traumatology for a CT and MRI of the cervical spine. This patient lives in the countryside and works as a logger. In January he suffered an industrial injury (a tree fell). He complained of neck pain and periodical numbness in his fingers at night. Before the trauma, during last 2-3 years, he had fatigue in the neck and occipital region. There were no additional complaints. Visually: there was an insignificant shortness of neck (Figure 1) and limited cervical range of motion.

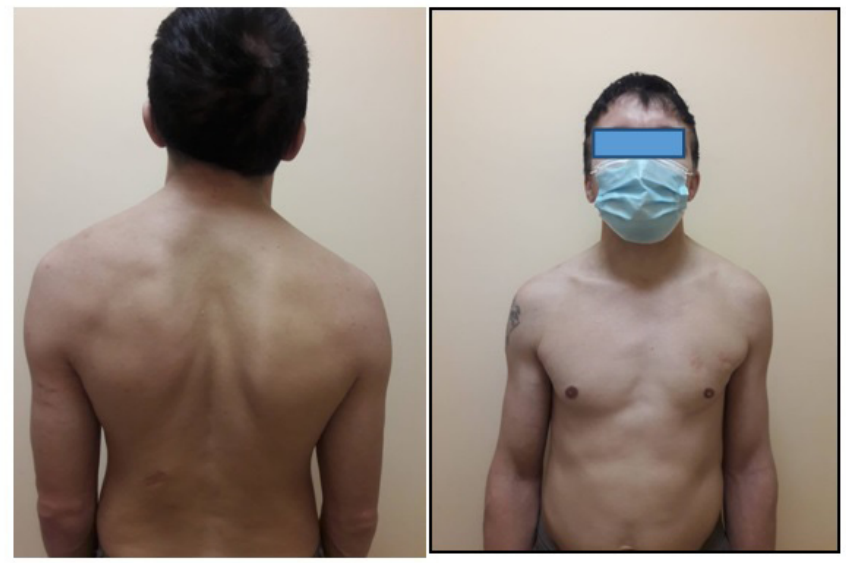

Fig. 1. The appearance of the KFS patient.

The cervical and upper thoracic CT (Siemens SOMATOM Scope Power) showed spina bifida anterior and posterior at the $\mathrm{C} 1$ with diastasis of $0.46-0.47 \mathrm{~cm}$; a full concrescense of C2-C3, C5-C6, C7-Th9 vertebrae, an anomaly of $\mathrm{C} 3$ as a left-side, hypoplasied, wedge-shaped half-vertebra. A cervical lordosis was transformed into a smooth kyphosis. There was a left-side scoliosis with the top of the curve at the Th3 level with a Cobb angle of $10^{\circ}$. The intervertebral discs between fused bodies were severely hypoplasied. There was a moderate stenosis of the spinal canal to $1.29 \mathrm{~cm}$ at the level of cranial plate of $\mathrm{C} 6$. The facet joints between fused vertebrae were consolidated, the joints between the blocks of fused bodies and the uncovertebral joints, also known as the joints of Luschka, had the signs of arthrosis. The posterior parts of the left third and fourth ribs were connected with a wide bone bridge (Figures 2 and 3).

MRI (Siemens MAGNETOM Espree 1.5T MRI System) showed disc herniations at $\mathrm{C} 3-\mathrm{C} 4$ and $\mathrm{C} 5-\mathrm{C} 6$. There were no pathological changes in the spinal cord (Fig.4).

The patient refused to make the genetic analysis, and got the recommendations for physiotherapy and the documents for the disability group.
In conclusion, $\mathrm{CT}$ and MRI permit us to visualize the pathologic changes in spine and spinal cord, to evaluate this anomaly. Therefore, it is possible to diagnose KFS, to choose a treatment to provide relief and to improve the quality of life, and to assess the disability group.
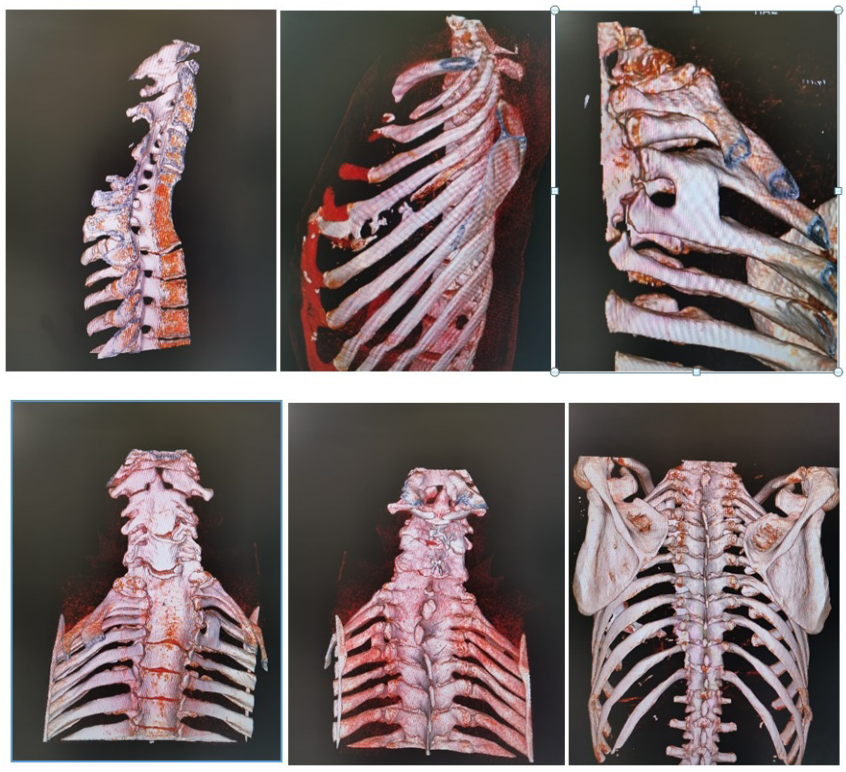

Fig. 2. Cervical and upper thoracic CT: $3 D$.

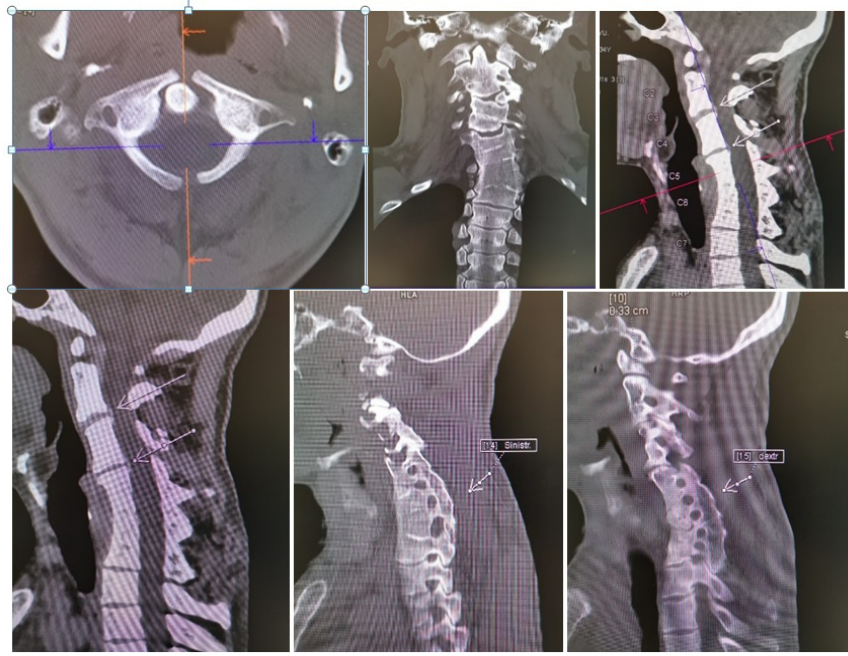

Fig. 3. Cervical and upper thoracic CT: MPR.
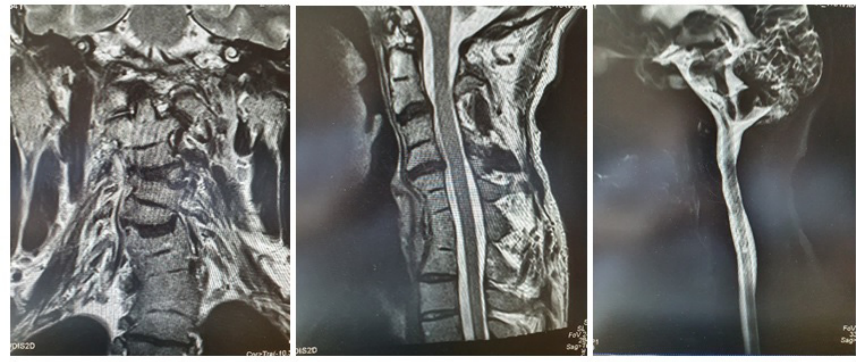

Fig. 4. Cervical and upper thoracic MRI. 


\section{Competing Interests} interests.

The authors declare that they have no competing

\section{References}

1. Tracy MR, Dormans JP, Kusumi K. Klippel-Feil syndrome: clinical features and current understanding of etiology. Clin Orthop Relat Res. 2004 Jul;(424):183-90.

2. McBride WZ. Klippel-Feil syndrome. Am Fam Physician. 1992 Feb;45(2):633-5.

3. Li Z, Zhao S, Cai S, Zhang Y, Wang L, Niu Y, Li X, Hu J, Chen J, Wang S, Wang H, Liu G, Tian Y, Wu Z, Zhang TJ; DISCO (Deciphering Disorders Involving Scoliosis and COmorbidities) study, Wang Y, Wu N. The mutational burden and oligogenic inheritance in Klippel-Feil syndrome. BMC Musculoskelet Disord. 2020 Apr 11;21(1):220. doi: 10.1186/ s12891-020-03229-x.

4. Power BD, Walsh KP, Awan A, Waldron M, O'Grady MJ. Klippel-Feil syndrome as a novel feature of Schimke immunoosseous dysplasia. Am J Med Genet A. 2019 May;179(5):862-863. doi: 10.1002/ajmg.a.61087.

5. Bejiqi R, Retkoceri R, Bejiqi H, Zeka N. Klippel Feil Syndrome Associated with Congenital Heart Disease. Presentation of Cases and a Review of the Current Literature. Open Access Maced J Med Sci. 2015 Mar 15;3(1):129-34. doi: 10.3889/oamjms.2015.022.

6. Edward JA, Psaltis AJ, Williams RA, Charville GW, Dodd
RL, Nayak JV. Endoscopic Resection of Skull Base Teratoma in Klippel-Feil Syndrome through Use of Combined Ultrasonic and Bipolar Diathermy Platforms. Case Rep Otolaryngol. 2017;2017:6384586. doi: 10.1155/2017/6384586.

7. Hitosugi T, Tsukamoto M, Yokoyama T. Anesthetic Management for Twice in a Child with Klippel-Feil Syndrome. Masui. 2017 May;66(5):554-557. [Article in English, Japanese]. 8. McLaughlin N, Weil AG, Demers J, Shedid D. KlippelFeil syndrome associated with a craniocervico-thoracic dermoid cyst. Surg Neurol Int. 2013 Mar 22;4(Suppl 2):S616. doi: 10.4103/2152-7806.109440.

9. Ogihara N, Takahashi J, Hirabayashi H, Mukaiyama K, Kato H. Surgical treatment of Klippel-Feil syndrome with basilar invagination. Eur Spine J. 2013 May;22 Suppl 3(Suppl 3):S380-7. doi: 10.1007/s00586-012-2489-3.

10. Pai D, Kamath AT, Kini P, Bhagania M, Kumar S. Concomitant Temporomandibular Joint Ankylosis and Maxillomandibular Fusion in a Child with Klippel- Feil Syndrome: A Case Report. J Clin Pediatr Dent. 2018;42(5):386390. doi: 10.17796/1053-4625-42.5.11.

11. Stelzer JW, Flores MA, Mohammad W, Esplin N, Mayl JJ, Wasyliw C. Klippel-Feil Syndrome with Sprengel Deformity and Extensive Upper Extremity Deformity: A Case Report and Literature Review. Case Rep Orthop. 2018 Jan 18;2018:5796730. doi: 10.1155/2018/5796730.

12. Tian Y, Fan D, Xu N, Wang S. «Sandwich Deformity» in Klippel-Feil syndrome: A «Full-Spectrum» presentation of associated craniovertebral junction abnormalities. J Clin Neurosci. 2018 Jul;53:247-249. doi: 10.1016/j. jocn.2018.04.047. 